\title{
Videolaparoscopia no diagnóstico e tratamento da síndrome do ovário remanescente em uma gata
}

\author{
Videolaparoscopic surgery in the diagnosis and treatment of remaining ovary in a cat
}

\author{
Bruna Lopes Finger ${ }^{\mathrm{I}}$ Maurício Veloso Brun ${ }^{\mathrm{II}}$ Lucas Marques Colomé ${ }^{\mathrm{II}}$ \\ Ricardo Oliveira Pimentel ${ }^{\mathrm{II}}$ João Pedro Scussel FerantiI
}

\begin{abstract}
A síndrome do ovário remanescente é definida como a persistência da atividade ovariana em fêmeas castradas. É decorrente da presença de tecido ovariano acessório no ligamento largo uterino ou por erro na técnica cirúrgica de ovariosalpingohisterectomia ou ovariectomia. O presente trabalho descreve o diagnóstico e tratamento videolaparoscópico de um caso de síndrome de ovário remanescente em uma gata. No acesso, foram utilizados três portais de $5 \mathrm{~mm}$ nas paredes abdominais direita, esquerda e na linha média ventral. Constatou-se a presença de massa com aspecto de tecido ovariano junto à fossa paralombar esquerda e aumento de volume na fossa paralombar direita, removidos com tesoura de Metzenbaum e cauterização monopolar. O exame histológico da massa extirpada do lado esquerdo confirmou a presença de tecido ovariano. Não se observaram complicações perioperatórias, e a paciente evoluiu sem sinais de recidiva de estro pelo período de pelo menos 24 meses. Conclui-se que a síndrome do ovário remanescente em gatas pode ser diagnosticada e tratada com sucesso por cirurgia laparoscópica.
\end{abstract}

Palavras-chave: cirurgia laparoscópica, ovário, felinos, estro.

\section{ABSTRACT}

Ovarian remnant syndrome (ORS) refers to the presence of functional ovarian tissue in a previously ovariohysterectomized animal. This report describes a case of remaining ovary syndrome in a cat that was submitted to ovariohysterectomy six months later. Three laparoscopic portals of $5 \mathrm{~mm}$ were created in the abdominal walls (in the right and left lateral abdominal flank, and one in the ventral abdominal midline). It was observed the presence of one mass in the site of ovarians region. Both tissues were removed using Metzenbaum scissors and monopolar cauterization. The histological examination demonstrated ovarian tissue in the left carried by side. The post-operative time was uneventful. The treatment of ovarian remnant syndrome in a cat can be successfully performed by laparoscopic surgery.

Key words: laparoscopic surgery, ovarian, feline, estrus.

A ovariosalpingohisterectomia (OSH) é o procedimento cirúrgico realizado com maior frequência em cães e gatos, sendo o método de eleição para esterilização desses animais (OLIVEIRA, 2007; SCHIOCHET et al., 2007). É também indicada como terapêutica cirúrgica de diversas doenças uterinas e/ ou ovarianas (FINGLAND, 1996). Em medicina humana, procedimentos cirúrgicos semelhantes, incluindo a execução de cirurgias robóticas pelo sistema Da Vinci®, também são realizados objetivando o tratamento de doenças do trato reprodutivo/genital feminino (DONNEZ et al., 2007; KHO et al., 2007).

A síndrome do ovário remanescente (SOR) teve seu primeiro caso reportado em humanos, em 1962, por Kaufmann, mas foi somente em 1970 que Shemwell e Weed a descreveram pela primeira vez (SONTAS, 2007). Em animais de companhia, a primeira descrição foi feita por Pearson, relatando a ocorrência de 12 casos (SONTAS, 2007).

IPós-graduação em Clínica e Técnica Cirúrgica Veterinária, Faculdade de Agronomia e Medicina Veterinária (FAMV), Universidade de Passo Fundo (UPF), 99052-900, Passo Fundo, RS, Brasil. E-mail: brunalopes@hotmail.com. Autor para correspondência.

"FAMV, UPF, Passo Fundo, RS, Brasil.

IIIHospital Veterinário, Universidade de Passo Fundo, Passo Fundo, RS, Brasil. 
A alteração é definida como a persistência da atividade ovariana em fêmeas castradas decorrente da presença de tecido ovariano acessório no ligamento largo uterino, ou mais comumente, por erro na técnica cirúrgica de OSH (MACEDO \& LOPES, 2003) ou ovariectomia (OV) (SONTAS, 2007). Alguns estudos apontam que a SOR é mais comum após OSH eletiva e ocorre mais frequentemente em gatas que em cadelas (MILLER, 1995; MACEDO \& LOPES, 2003). Anatomicamente, o ovário e corno uterino direito são mais craniais e, portanto, mais difíceis de serem exteriorizados. Este fato poderia estar relacionado a uma ocorrência maior de persistência de tecido ovariano no lado direito, mas essa condição não foi reportada por MILLER (1995) em seu estudo. O diagnóstico de síndrome do ovário remanescente pode ser confirmado por citologia vaginal, ultrassonografia, dosagens hormonais e cirurgia exploratória, sempre associando a história e os sinais clínicos de ocorrência de cio no animal. O presente trabalho objetiva relatar a aplicação da cirurgia laparoscópica no diagnóstico e tratamento da SOR, em uma gata previamente submetida à OSH convencional.

Uma gata sem raça definida, com três anos de idade, foi encaminhada ao Hospital Veterinário da Universidade de Passo Fundo apresentando sinais de cio (vocalização, lordose e atração por machos) seis meses após realização de OSH eletiva por técnica aberta. Não foram verificadas alterações no leucograma e eritrograma pré-operatórios. Considerando o objetivo diagnóstico e a possibilidade de execução do tratamento, optou-se pela realização da videolaparoscopia exploratória.

Como medicação pré-anestésica, foi utilizada a associação de tiletamina com zolazepam (5mg kg-1, IM). Para indução anestésica, utilizou-se propofol (3mg $\mathrm{kg}^{-1}, \mathrm{IV}$ ) e na manutenção, halotano vaporizado em oxigênio a $100 \%$, em sistema reinalatório.

Na região pré-umbilical da linha média ventral, a $1 \mathrm{~cm}$ da cicatriz umbilical, realizou-se incisão de pele medindo $6 \mathrm{~mm}$. Pela técnica aberta, foi inserido um trocarte de $5 \mathrm{~mm}$, obtendo-se a insuflação de $\mathrm{CO}_{2}$ medicinal $\left(1 \mathrm{~L} \mathrm{~min}^{-1}\right)$ até alcançar a pressão intracavitária de $12 \mathrm{mmHg}$. Sob visão endoscópica (com endoscópio de 0 grau e $5 \mathrm{~mm}$ acoplado à microcâmera e à fonte de luz), foram escolhidos os sítios de posicionamento dos demais trocartes $(5 \mathrm{~mm})$, sendo as punções realizadas nas paredes abdominais laterais direita e esquerda. Em seguida, inspecionou-se a cavidade abdominal e constatou-se massa com aspecto de tecido ovariano junto à fossa paralombar esquerda (Figura 1), aderida ao mesovário remanescente e ao omento maior. Optouse pela extirpação do tecido, com margem de segurança, por meio de pinça Kelly e tesoura de Metzenbaum (auxiliada por cauterização monopolar). O fragmento foi acondicionado em saco para a remoção de tecidos, confeccionado a partir de dedo de luva tamanho 8,5 e sutura em bolsa-de-tabaco na extremidade. O saco foi introduzido pelo orifício do portal lateral direito. Repetiu-se a inspeção na fossa paralombar direita, permitindo a verificação de tecido alterado junto ao resquício de mesovário. A remoção do material foi similar à descrita previamente.

Verificando-se ausência de hemorragia, a cavidade foi desinsuflada, e as feridas foram suturadas em nível muscular e subcutâneo, em padrão Sultan com fio poliglactina 910 2-0. A pele foi suturada com náilon monofilamentar 4-0, em padrão interrompido simples.

A intervenção cirúrgica teve duração de 60 minutos e não ocorreram complicações perioperatórias. Posteriormente, o exame histológico confirmou a presença de folículos ovarianos e corpo lúteo no tecido coletado do lado esquerdo. Já na massa extirpada da fossa paralombar direita, observou-se ausência de tecido ovariano e presença de fragmentos de corno uterino envolvidos por tecido fibroso.

SOR refere-se à presença de tecido ovariano residual em animais ovariohisterectomizados ou ovariectomizados de forma incompleta (MILLER,1995; FINGLAND, 1996; HEDLUND, 2005). As alterações comportamentais observadas no paciente antes da abordagem cirúrgica e a presença de tecido ovariano e uterino demonstram que o primeiro procedimento foi tecnicamente inadequado, necessitando de nova intervenção. A remoção dos fragmentos com margem de segurança, aliada à ausência de sinais de cio pósoperatório, confirmaram o sucesso da terapia. Optouse pela videolaparoscopia pela possibilidade de confirmação diagnóstica e estabelecimento do tratamento cirúrgico durante a mesma intervenção. Além disso, a escolha também foi fundamentada na magnificação de imagens e possibilidade de exploração ampla da cavidade peritoneal, condição útil na localização de massas pequenas. Na suspeita de tecidos ovarianos remanescentes, os primeiros locais a serem inspecionados são as fossas paralombares, caudalmente ao pólo caudal do rim, uma vez que essa é a localização anatômica do mesovário. Caso haja dificuldades de exposição da região com o paciente em decúbito dorsal, pode-se rotacionar o paciente médiolateralmente a partir da fixação conjunta dos membros anteriores em um dos lados da mesa operatória. Tal manobra promove adequado deslocamento medial das vísceras abdominais e ampla exposição do local de inserção dos ovários (SILVA, 2008).

A utilização de saco para a remoção de tecidos confeccionado a partir de dedo de luva cirúrgica (BRUN et al., 2002) se mostrou apropriada, porém difere 


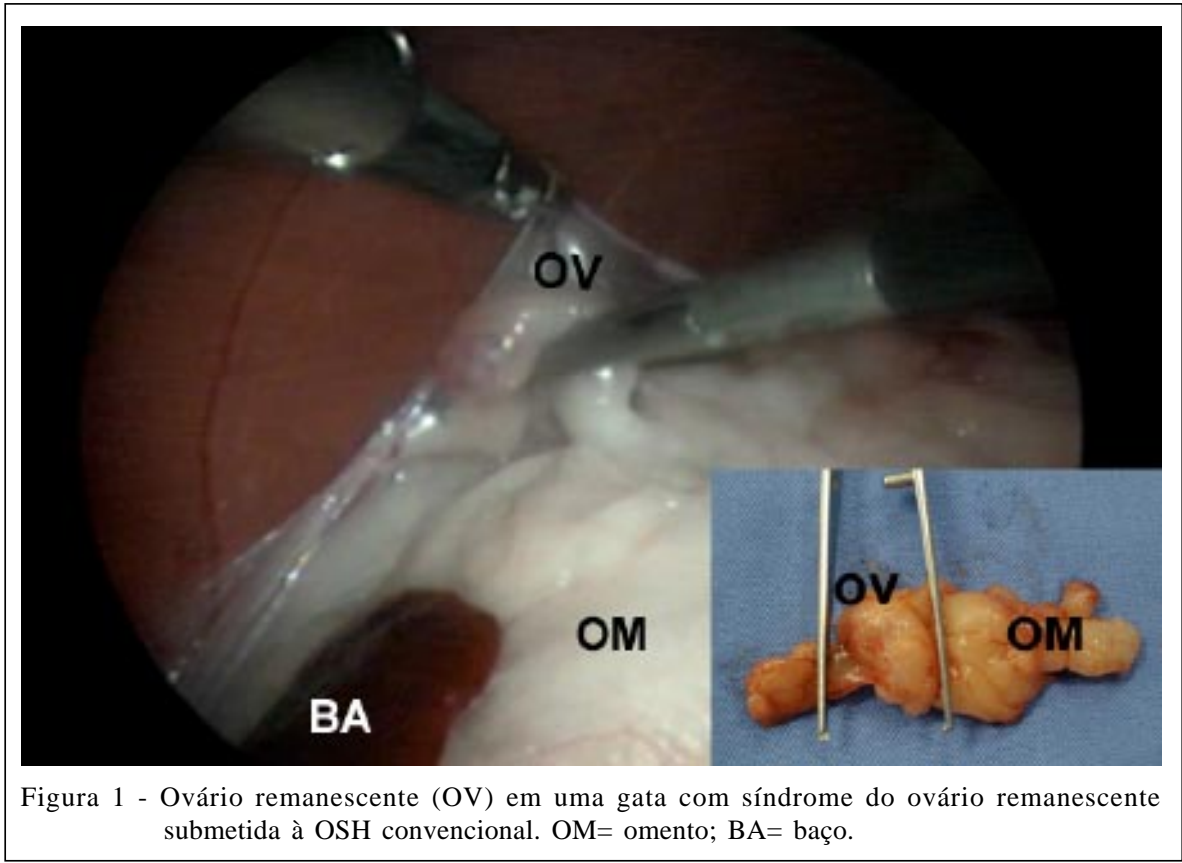

do descrito por SCHIOCHET et al. (2007). No presente caso, foram utilizados apenas trocartes de $5 \mathrm{~mm}$, e as dimensões das feridas associadas a estes não permitiriam a remoção do tecido alterado sem contato, sob tensão, com a parede abdominal (o que poderia resultar em disseminação de tecido ovariano), ou sem a ampliação do acesso cirúrgico. Além disso, o animal possuía cavidade peritoneal pequena, a qual não comportaria os sacos industrializados disponíveis. Outra diferença em relação ao relato anterior (SCHIOCHET et al., 2007) é a utilização de cauterização monopolar, a qual se mostrou eficaz e segura, considerando-se a diminuta espessura do tecido extirpado e a aplicação cautelosa da energia elétrica.

O presente caso confirmou a eficácia da videolaraposcopia como ferramenta diagnóstica e terapêutica na síndrome do ovário remanescente em uma gata.

\section{REFERÊNCIAS}

BRUN, M.V. et al. Confecção de saco para a remoção de tecidos em cirurgia laparoscópica utilizando dedo de luva. In: CONGRESSO BRASILEIRO DE CIRURGIA E ANESTESIOLOGIA VETERINÁRIA, 5., 2002, Rio de Janeiro. Revista Brasileira de Ciência Veterinária. Rio de Janeiro: Universidade Federal Fluminense, 2002. V.9, p.175-177.

DONNEZ, O. et al. Primary ovarian adenocarcinoma developing in ovarian remnant tissue ten years after laparoscopic hysterectomy and bilateral salpingo-oophorectomy for endometriosis. Journal of minimally invasive gynecology, v.14, p.752-757, 2007. Disponível em: <http://www.jmig.org/ article/S1553-4650(07)00204-X/abstract>. Acesso em: 15 abr. 2008. doi:10.1016/j.jmig.2007.05.005.
FINGLAND, R.B. Ovário-histerectomia. In: BOJRAB, M.J. Técnicas atuais em cirurgia de pequenos animais. 3.ed. São Paulo: Roca, 1996. p.375-381.

HEDLUND, CS. Cirurgia dos sistemas reprodutivo e genital. In: FOSSUM, T.W. Cirurgia de pequenos animais. 2.ed. São Paulo: Roca, 2005. p.619-672.

KHO, R.M. et al. Pathologic findings and outcomes of a minimally invasive approach to ovarian remnant syndrome. Fertility and Sterility, v.87, n.5, p.1005-1009, 2007. Disponível em: <http://www.fertstert.org/article/S00150282(07)00057-X/abstract>. Acesso em: 21 jun. 2008. doi: 10.1016/j.fertnstert.2006.12.075.

MACEDO, L.P.; LOPES, M.D. Síndrome do ovário remanescente em cadelas: revisão. Clínica Veterinária, São Paulo, n.44, p.22-24, 2003.

MILLER, D.M. Ovarian remnant syndrome in dog and cat Journal of Veterinary Investigation, v.7, p.572-574, 1995.

OLIVEIRA, K.S. Síndrome do ovário remanescente. Acta scientiae veterinarie, v.35, supl.2, p.273-274, 2007.

SCHIOCHET, F. et al. Ovariectomia laparoscópica em uma gata com ovários remanescentes. Acta Scientiae Veterinariae, v.35, n.2, p.245-248, 2007.

SILVA, M.A.M. Avaliação laparoscópica das aderências intraperitoneais pós-cirúrgicas em cadelas: emprego de duas doses de solução de azul de metileno a $1 \%$ na profilaxia. 2008. 74f. Dissertação (Mestrado em Ciência Animal) - Escola de Veterinária, Universidade Federal de Goiás. Goiânia, MG.

SONTAS, B.H. Ovarian remnant syndrome in the bitch: a literature review. Archivos de Medicina Veterinaria, v.39, n.2, p.99-104, 2007. Disponível em: <http://www.scielo.cl/ scielo.php ? s c ript = sci arttext \& pid = S 0301 $732 X 2007000200002 \& \operatorname{lng}=\mathrm{es} \& \mathrm{nrm}=\mathrm{iso}>$. Acesso em 18 mai. 2008. 